\title{
Georges Perec: UMA POÉTICA DA RE-ESCRITURA
}

\author{
por Carolina Augusto Messias ${ }^{1}$
}

\begin{abstract}
RESUMO: Este artigo apresenta a fase inicial de minha pesquisa na Iniciação Científica, cuja questão principal é entender a re-escritura como um dos cernes da poética perecquiana. A partir dessa discussão, pretendo mostrar de que forma ocorre o processo de re-apropriação de Flaubert, levantar hipóteses sobre os motivos da escolha desse autor do séc. XIX como um dos 'modelos' do primeiro livro de Georges Perec, Les Choses (1965) e discutir o valor literário da citação.
\end{abstract}

PALAVRAS-CHAVE: Georges Perec, Re-escritura, Les Choses (1965).

RÉSUMÉ: Cet article présente le début de ma recherche d'Initiation Scientifique, dont la question principale est essayer d'analyser la réécriture comme l'un des points cruciaux de la poétique perecquienne. À partir de cette discussion, j’envisage de démontrer quelle est la procédure de reappropriation de Flaubert par Perec, relever des hypothèses à propos du choix de cet écrivain du XIXe siècle comme l'un des 'modèles' du premier roman de Georges Perec, Les Choses (1965) et discuter la valeur littéraire de la citation.

MOTS CLÉS: Georges Perec, Réécriture, Les Choses (1965).

"L'auteur n'est pas quelqu'un à qui tout est donné d'avance"

L.G., Perec

Cada um tem seus modelos: para alguns, os clássicos; para outros, os românticos, ou ainda, os realistas. A questão é que nenhum romance, nenhuma poesia é produto da Musa inspiradora, mas de um trabalho árduo do qual não se pode fugir. Por que então escrever se, na verdade, estamos re-escrevendo as idéias de outros, os discursos de outros, as histórias de outros? É que o trabalho do escritor é artesanal, isto é, $10 \%$ é criatividade, os outros $90 \%$ é trabalho braçal, e nem por isso menos importante do que imaginamos.

A questão da originalidade é tipicamente romântica, apesar de estar presente desde o Iluminismo, quando a palavra assume a posição de identidade do Poeta e que, portanto, precisa ter o estatuto de exclusividade (BLOOM, 1991, p.105). Contudo, no romantismo, essa idéia de que o Poeta deve ser original torna-se mais presente quando ele está ligado à figura do "Gênio romântico", detentor de uma verdade que ele descobriu.

Como analisar, então, o livro de um escritor francês que em 1967 declarara abertamente seu desejo de ser um escritor realista, além de apontar quais são os escritores que ele tomou como "modelos" de seu primeiro livro? Georges Perec é o nome desse escritor, que tem seu primeiro livro, Les Choses, publicado e premiado em 1965, e convidado a integrar o grupo OuLiPo a partir de 1967.

Com as questões impostas pela literatura e crítica do final do séc. XIX e início do XX, dentre elas as idéias de Blanchot sobre o desaparecimento da literatura, o fracasso, a inutilidade da busca das personagens nos romances, há uma mudança radical desse conceito de originalidade. Por exemplo, a escritura para Perec é um ato cultural e não uma questão de inspiração ou de uma ajuda mística, não é algo natural. Após colocar que essa idéia de uma

\footnotetext{
${ }^{1}$ Graduanda do curso de Letras Português/ Francês da FFLCH - USP, membro do Grupo Criação \& Crítica, da mesma instituição e bolsista da Fundação de Amparo à Pesquisa (FAPESP).
} 
voz inspiradora deve ser questionada, ele escreve num quadro quais são os modelos de seu Les Choses (PEREC: 1967) ${ }^{2}$ :

\section{FLAUBERT Les Choses NIZAN ANTELME $\quad$ BARTHES}

A partir desses nomes que enquadram o primeiro romance perecqueano, podemos nos questionar sobre qual a importância de um livro que se baseia em outros, imitando e "copiando" trechos, ultrapassando o limite do conceito de 'influência' defendida por Lanson $(1965)^{3}$, já que há diversos 'fatos' que comprovam a presença de outros textos em Les Choses, e mais, o autor não esconde isso de ninguém.

As leituras de Nizan et Barthes (de Mythologies), afirma Perec em entrevista à Leslie Hill, contribuíram do ponto de vista ideológico. Já Antelme e Flaubert podem ser "encontrados" no nível frasal; o romance L'Espèce humaine, do primeiro, trata da realidade dos campos de concentração, criticamente e sem pieguices. Semelhante, portanto, à (ir)realidade da sociedade de consumo a que estavam presos Jerôme e Sylvie de Les Choses. De Flaubert, que é nosso maior interesse aqui, Perec afirma ter se apropriado de imagens, de cenas de $L^{\prime}$ Éducation sentimentale, dentre as quais ele revela três, especificamente: um leilão, uma viagem de barco e uma manifestação política. Além de também ter construído suas frases no ritmo ternário e ter "copiado" trechos sem empregá-los entre aspas.

Pensando neste livro como um projeto de re-criação de seus modelos, adotaremos o conceito de re-escritura como o mais apropriado para entendermos a re-apropriação empreendida por Perec em seu primeiro livro. Réécriture ou Récriture, o termo surge na França, a partir da década de 1980 paralelamente ao advento da crítica genética e refere-se ao trabalho de um escritor que se apropria e transforma o texto-base.

No artigo "De l'intertextualité à l'écriture", Gignoux (2006) discute a questão da intextertualidade ligada à variedade de leituras e experiências. Para ela, os textos compõem um amplo diálogo uns com os outros e, talvez, algumas referências do autor sejam impossíveis de serem resgatadas porque não são apenas leituras de outros autores clássicos, mas de todo um repertório cultural também ligado ao discurso cotidiano (dos jornais), como ao discurso familiar, aos grupos de literatura, ou seja, é um diálogo com sujeitos que possuem outros discursos e, nesse ponto, estaria a dificuldade de estudar a intertextualidade, por estar ligada a um domínio muito subjetivo da linguagem. Já no caso da re-escritura pressupomos, na maioria dos casos, um aspecto programático no ato de reescrever, o que, nesse sentido, estaria ligada à produção do texto.

Se a noção de influência parece estar ligada à idéia de um texto acabado, fechado em si e que é retomado por outro, o conceito de re-escritura pressupõe o contrário: a idéia de que o livro (ou a literatura, num sentido mais amplo) não está acabado, mas carrega em si uma

\footnotetext{
${ }^{2}$ PEREC, G. « Pouvoirs et Limites du romancier français contemporain » in RIBIÈRE, M (org).Parcours Perec - Colloque de Londres (mars 1988), Lyon: Presses Universitaires de Lyon, 1990, p.34. Trata-se de uma conferência proferida por Georges Perec em 5 de maio de 1967 na Universidade de Warwick (Coventry, Reino Unido) em que ele fala da sua experiência de escritor, como se tornou escritor e apresenta seus modelos.

${ }^{3}$ Em «Sur la notion d'influence », Lanson (1965) afirma que a verdadeira influência é marcada mais pela penetração dos gênios do que pela materialidade dos empréstimos e o que comprova sua existência são "cores e formas de pensamento" e não algum fato concreto.

${ }^{4} \mathrm{O}$ artigo de Gignoux consta no número 13 dos Cahiers é inteiramente dedicado ao estudo da intertextualidade e da re-escritura, tanto na literatura como na crítica literária.
} 
potencialidade, ou seja, a possibilidade de, a partir de certos mecanismos aplicados sobre um texto-base, obtermos um texto completamente inesperado:

Todas essas manipulações (trato dos oulipismos) se fiam num princípio 'maquinal' (poderíamos inventar outros deles) para tirar do hipotexto (batizado por Perec como «texto origem ») um texto totalmente diferente do ponto de vista lexical. (GENETTE, 1982, p.63) ${ }^{5}$

Sabe-se que no séc. XX, sobretudo, os escritores começaram a "atacar" a linguagem em suas obras a fim de investigarem novos sentidos que essa poderia oferecer. Os trabalhos do OuLiPo, fundado em 24 de novembro de 1960, são primordiais na busca desses novos efeitos através da criação das contraintes: os lipogramas, poesias-matemáticas, romances que parecem criar uma armadilha para o leitor, etc.

A obra de Perec, desde Les Choses (1965), está inserida num contexto em que a linguagem é uma questão tanto da literatura, do final do séc. XIX, como da crítica, principalmente a partir de 1930, com Proust propondo que a única forma de crítica é imitar o estilo de outros autores, ou seja, a partir do séc. XX a crítica literária também pode ser discutida como criação literária. Nesse sentido, há uma discussão formal da crítica que não precisa ser um ensaio com regras acadêmicas restritas, e pode sim ser uma crítica-criativa, uma (literatura) ${ }^{2}$. Desse modo, crítica e literatura começam a se confundir e não sabemos até que ponto a primeira ultrapassa os limites da segunda.

A proposta de re-criação, assim como a nova crítica, também é (literatura) ${ }^{2}$. Simplificando ao extremo, re-escritura é a apropriação e transformação de um texto base, logo seu princípio é o mesmo da crítica: a sedução por determinado texto ou autor. Mas qual será o principal motivo da recriação literária?

A re-escritura pressupõe os três passos de uma leitura crítica: a vontade de prolongar o outro, o desejo de SER o outro e o reconhecimento de repetições. Essa vontade já foi manifestada por diversos escritores, principalmente os do séc. XX, como Proust, em Pastiches et Mélanges (1935), Queneau, em Exercices de style (1948), e Perec, que será nosso grande representante desse "voloir-être", já que sua trajetória literária não pode deixar de ser analisada sem a presença de seus 'modelos'.

Les Choses (1965) é uma escolha interessante para começar o estudo da poética perecqueana porque Perec já havia deixado o projeto da revista La Ligne Générale (L.G.), nome referente ao filme de Eisenstein, e que surgiu entre 1959 e 1963 quando o escritor e alguns amigos ambicionaram (re)fundar a estética marxista; e ainda não havia ingressado no Oulipo, o que só acontecerá em 1967. Segundo Burgelin, no prefácio a L. G. - une aventure des années soixante, de G. Perec,

(...) aparentemente o Perec oulipiano pouco tem a ver com o Perec da Ligne Générale. Resta entretanto que através de seus textos, observa-se a organização dos pilares sobre os quais ele vai edificar o essencial de sua obra, com evidentes continuidades na escolha dos fios condutores. (BURGELIN, 1992, p.20.) ${ }^{6}$.

\footnotetext{
5 “Toutes ces manipulations (je parle des oulipiennes s'en remettent à un principe «machinal» (on pourrait en inventer d'autres) pour tirer de leur hypotexte (baptisé par Perec «texte souche ») un texte lexicalement tout différent. » (tradução nossa)

6 “(...) apparemment, le Perec oulipien a peu à voir avec le Perec de La Ligne Générale. Reste pourtant qu à travers ces textes, on voit se mettre en place les pilotis sur lesquels il va édifier l'essentiel de son oeuvre, avec d'évidentes continuités dans le choix de fils conducteurs ». (tradução nossa).
} 
É interessante estudar Les choses para começar a entender esses pilares em que está fundada sua obra e a forma que ele escolheu para trabalhar as questões de sua geração de 1960:

Já agora ele sabe também que todo romance da conquista passa antes por uma reconquista da língua em si, por uma crítica e uma renovação das formas narrativas. Daquela 'crise da linguagem', ele tirará a mais precisa lição já que ele escolherá, graças ao Oulipo e à submissão às mais exigentes contraintes formais, uma forma radical, ambígua e irônica de remediá-la. Sua constante retomada às regras formais e aos princípios de arquitetura mostram seu apego às lições de Eisenstein declarando que 'o princípio de organização do pensamento constitui de fato o verdadeiro conteúdo da obra'.( BURGELIN, 1992, p.21)

'Princípio de organização' que ele não escondeu naquela conferência aos estudantes da Universidade de Warwick ao citar os nomes de Barthes, Nizan, Anthelme e Flaubert. Nomes que anunciam o modo como Perec concebe seu Les Choses, tanto do ponto de vista ideológico como formal, já que ele acredita que a literatura é criada através da consideração e transformação (olhar crítico) dos discursos que já existem:

A literatura começa assim, assim que começa, pela linguagem, dentro da linguagem, aquela transformação de forma alguma evidente ou imediata, que permite a um indivíduo tomar consciência exprimindo o mundo, se endereçando aos outros. (PEREC, 1992, p.114)

\section{MAS POR QUE SE ‘ENDEREÇAR’ A FLAUBERT?}

Perec já havia anunciado seu desejo de ser um escritor realista em 1967, e realismo para o escritor não é representarivo, mas citacional. Sobre o "real" em Perec, afirma Leslie Hill (1990):

O real se torna (nos termos que Perec começa a utilizar aqui pela primeira vez) um labirinto textual, um quebra-cabeça cujas peças são os outros textos. O escritor apenas transforma um mundo já representado, um mundo habitado e atravessado do um extremo ao outro por outros espaços, outras estruturas, outros escritos.( HILL, L. 1990, in RIBIÈRE, M. (org.), p.28) ${ }^{9}$

\footnotetext{
7 "D’ores et déjà il sait aussi que tout roman de la conquête passe d'abord par une reconquête de la langue même, par une critique et un renouveau des formes narratives. De cette «crise du langage », il tirera la plus précise des leçons puisqu'il choisira, grâce à l'Oulipo et à la soumission aux contraintes formelles les plus astreignantes, une façon radicale, ambigüe et narquoise d'y remédier. Son recours constant à des règles formelles et à des principes d'architecture montre son attachement aux leçons d'Eisenstein déclarant que «le principe d'organisations de la pensée constitue en fait le véritable contenu de l'oeuvre. » (tradução nossa).

8“La littérature commence ainsi, lorsque commence, par le langage, dans le langage, cette transformation, pas du tout évident et pas du tout immédiate, qui permet à un individu de prendre conscience, en exprimant le monde, en s’addressant aux autres ». (tradução nossa.)

9 "Le réel devient (en des termes que Perec commence à utiliser ici pour la première fois) un labyrinthe textuel, un puzzle dont les pièces sont les autres textes. L'écrivain ne fait que transformer un monde déjà représenté, un
} 
Mas a pergunta que surge ao lermos Les Choses é: por que Perec resolveu se "endereçar" justamente ao discurso flaubertiano? Para Perec, o realismo é descrição da realidade, "é mergulhar nela e lhe dar forma, é atualizar a essência do mundo : seu movimento, sua história." (PEREC, 1992, p.51) ${ }^{10}$. Ora, quem melhor do que Flaubert imprimiu em seus textos o amor pela contemplação?

Além disso, o discurso de Flaubert é célebre tanto no meio acadêmico como entre os leitores comuns (não há quem não conheça, no mínimo, a história de Mme Bovary, mesmo sem nunca ter lido o livro). Discurso de um realista-moderno (apesar de Flaubert não gostar da primeira designação) que conseguiu escrever negando a própria existência da narrativa: o uso do imparfait para contar os fatos passados nos dá a impressão de uma narração contínua, perpétua e consequientemente impossível. Além de tratar do fracasso dos objetos, descritos à exaustão e dispostos de uma forma peculiarmente acumulativa que não sabemos como todos podem coexistir num determinado quarto ou estante...

Proust (1920) aponta, em seu ensaio "À propos du 'style' de Flaubert", algumas características da beleza gramatical do estilo do escritor do séc. XIX num trabalho de linguagem totalmente inovador, exemplificando com trechos de Madame Bovary $\mathrm{e}$ $L ' E ́ d u c a t i o n ~ s e n t i m e n t a l e$, em que a conjunção "et" e a vírgula posssuem um valor sistemático de adição e ritmo, além de revelar, juntamente ao uso do imparfait, a subjetividade de Flaubert:
O subjetivismo de Flaubert se exprime pelo novo emprego dos tempos dos verbos, das preposições, dos advérbios, os dois últimos tendo quase sempre na frase um valor rítmico. Um estado que se prolonga é indicado pelo imperfeito. Toda aquela segunda página da Educação [sentimental] (página escolhida absolutamente ao acaso) é feita de imperfeitos, exceto quando uma mudança intervém, uma ação, uma ação cujos protagonistas são geralmente coisas. (PROUST, 1920, s/ p. ) ${ }^{11}$

É a lógica dos objetos que já emergia no final do séc XIX e que culminará no mundo de coisas de Perec. O escritor contemporâneo se apropria de trechos de Flaubert e atualiza a discussão da reificação dos objetos, elevando-os ao extremo como personagens principais de seu romance.

A descrição inicial de um apartamento onírico, que seguirá initerruptamente pelas seis primeiras páginas do romance, lembra muito o modo como Flaubert contempla os objetos em sua obra:

O olho, inicialmente, deslizaria sobre o carpete cinza de um longo corredor, alto e estreito. As paredes teriam armários embutidos de madeira clara, cujas ferragens de cobre brilhariam. Três gravuras, uma

\footnotetext{
monde habité et traversé de part en part par d'autres espaces, d’autres structures, d’autres écrits. » (tradução nossa)

10 “c'est plonger en elle et lui donner forme, c'est mettre à jour l'essence du monde: son mouvement, son histoire. » (tradução nossa)

11 «Le subjectivisme de Flaubert s'exprime par un emploie nouveau des temps des verbes, des prépositions, des adverbes, les deux derniers n'ayant presque jamais dans sa phrase qu'une valeur rythmique. Un état qui se prolonge est indiqué par l'imparfait. Tout cette deuxième page de L'éducation (page prise absolument au hasard) est faite d'imparfaits, sauf quand intervient un changement, une action, une action dont les protagonistes sont généralmente des choses (« la colline s’abaissa », etc)». (Tradução e grifo nossos)
} 


\begin{abstract}
representando Thunderbird, vencedor em Epsom, a outra um navio de roda, $o$ Ville-de-Montereau, a terceira uma locomotiva de Stephenson, levariam a uma tapeçaria de couro, sustentada por grossos anéis de madeira escura cheia de veios, e que um simples gesto bastaria para movimentar. $O$ carpete, aqui, daria lugar a um assoalho quase amarelo, que seria coberto parcialmente por três tapetes de cores apagadas. (PEREC, 1965, p.9) ${ }^{12}$
\end{abstract}

Utilizando a classificação proposta por Genette esse trecho seria um pastiche, ou seja, a imitação não-satírica do estilo de um autor. Também encontramos no excerto uma alusão à embarcação Ville-de-Montereau, presente na primeira página de L'Éducation sentimentale.

Os verbos de ação para objetos e o uso da conjunção "et" e da vírgula enumerativas são próprios do estilo flaubertiano. Mas há nesse pastiche de Perec uma mudança significativa: a escolha dos tempos verbais. A mudança de um imparfait, que perpetualiza as descrições, para um conditionnel é substancial, já que este é o tempo da ilusão, do sonho, do irreal. Se "a modernidade começa com a busca de uma literatura impossível"(BARTHES, 1953, p.51), a narrativa aqui é totalmente colocada em xeque agora com descrições e fatos que nem sequer aconteceram, por exemplo no momento em que o casal Jerôme et Sylvie imaginam que poderiam receber uma herança de um tio, inesperadamente:

"Um dia, a 12 de dezembro de 1845 , pelas nove horas da manhã, a cozinheira levou-lhe uma carta ao quarto. O sobrescrito, de letra graúda, era de mão desconhecida; e Frederico, mal acordado, não se apressou a abri-la. Enfim leu :

Justiça de Paz do Havre. Terceiro Distrito.

«Senhor :

«Tendo o senhor Moreau, seu tio, morrido $a b$ intestado...»

Herdava!

Como se um incêndio se tivesse manifestado por trás das paredes, saltou da cama, descalço, em camisa : passou a mão pelo rosto, duvidando dos próprios olhos, julgando sonhar ainda, e, para se firmar na realidade, abriu a janela.» (FLAUBERT, s/ data, trad. rev. e adapt. pelo Departamento Editorial de W. M. Jackson Inc, p.101-2)

"Un jour, le 12 décembre 1845, vers neuf heures du matin, la cuisinière monta une lettre dans sa chambre. L'adresse, en gros caractères, était d'une écriture inconnue; et Frédéric, sommeillant, ne se pressa pas de la décacheter. Enfin il lut :

« Justice de paix du Havre. IIIe arrondissement. «Monsieur,
«Seria uma manhã como as outras. Sob a porta da entrada estariam três envelopes, compridos e estreitos, com timbres imponentes, gravados em relevo, sobrescritos precisa e regularmente, batidos numa máquina IBM. Suas mãos tremeriam um pouco ao abri-los: seriam três cheques, com uma seqüência de cifras. $\mathrm{Ou}$ então, uma carta:

"Prezado senhor:

Tendo o sr. Fulano, seu tio, morrido $a b$ intestat..."

E eles passariam a mão pelo rosto, duvidando do que seus olhos viam, ainda acreditando sonhar; abririam totalmente a janela." (PEREC; Netto, T. C. (trad.), 1969. p.83.)

"Ce serait une matinée comme les autres. Sous la porte d'entrée on aurait glissé trois enveloppes, longues et étroites, aux entêtes imposants, gravés, en relief, aux suscriptions précises et régulières, frappées sur une I.B.M. direction. Leurs mains trembleraient un peu en les ouvrant: ce serait trois chèques, avec des ribambelles de chiffres. Ou bien, une lettre : «Monsieur,

\footnotetext{
12 "L'oeil, d'abord, glisserait sur la moquette grise d'un long corridor, haut et étroit. Les murs seraient des placards de bois clairs, dont les ferrures de cuivre luiraient. Trois gravures, représentant l'une Thunderbird, vainqueur Epsom, l'autre un navire à aubes, le Ville-de-Montereau, la troisième une locomotive de Stephenson, mèneraient à une tenture de cuir, retenue par de gros anneaux de bois noir veiné, et qu'un simple geste suffirait à faire glisser. La moquette, alors, laisserait place à un parquet presque jaune, que trois tapis aux couleurs éteintes recouvriraient partiellement. »
} 
« M. Moreau, vontre oncle, étant mort $a b$ intestat...»

Il héritat!

Comme si un incendie eût éclaté derrière le mur, il sauta hors de son lit, pieds nus, en chemise ; il se passa la main sur le visage, doutant de ses yeux, croyant qu'il rêvait encore, et, pour se raffermir dans la réalité, il ouvrit la fenêtre toute grande. » (FLAUBERT [1869], 1998, p.130)
«M. Podevin, votre oncle, étant mort $a b$ intestat... » et ils passeraient la main sur le visage, doutant de leurs yeux, croyant rêver encore; ils ouvriraient la fenêtre toute grande. » (PEREC, 1965, p.100-1)

Diversos elementos da segunda coluna são explicitamente iguais aos da primeira, nos revelando a apropriação de Flaubert por Perec numa transposição: nos dois casos é manhã, a carta é igualmente estruturada, e tanto Frédéric como o casal de Les Choses não acreditam naquele milagre, passam as mãos pelo rosto e abrem uma grande janela. No entanto, a cena de cada livro acontece num contexto diferente; em L'Éducation sentimentale Frédéric recebe uma herança inesperada, quando Mme Moreau passava por dificuldades financeiras, e pode, assim, voltar à Paris, já em Les Choses, observamos Jerôme et Sylvie sonhando com uma grande herança que nunca receberiam.

O silêncio característico do estilo flaubertiano, e uns dos motivos da beleza e sedução de sua escritura, também aparece em Les Choses. Em Flaubert há uma suspensão da narrativa em "momentos duplamente silenciosos", usando as palavras de Genette (1966), já que as personagens cessam o diálogo para contemplar o mundo ou devanear, enquanto que em Les Choses, as personagens simplesmente não têm voz de tão sufocadas que estão pela ânsia do dinheiro e presas num devaneio constante:

O dinheiro levantava-se entre eles. Era uma parede, uma espécie de batente contra o qual vinham se chocar a todo instante. Era algo pior que a miséria : o embaraço, a estreiteza, a magreza. ${ }^{13}$ (PEREC; NETTO (trad.), 1969, p.64)

Podiam sem dúvida falar de outra coisa, de um livro recentemente leançado, de um diretor, da guerra, ou dos outros, mas parecia-lhes às vezes que as únicas conversas verdadeiras que tinham diziam respeito ao dinheiro, ao conforto, à felicidade. (idem, p.65)

O projeto flaubertiano de ne rien dire, que inaugura a experiência literária moderna, é continuado por Perec na tentativa de escrever um livro sobre nada, uma história sem sujeito, de realmente chegar a uma literatura impossível.

Depois dessas características gerais é preciso reforçar, no entanto, que Perec não reescrever qualquer romance de Flaubert, mas elege L'Éducation sentimentale como como modelo para Les Choses. O motivo? A pista para começar a responder a essa pergunta pode estar no título, ou melhor, no sub-título:

\section{L'Éducation sentimentale}

- Histoire d’un jeune homme -

\footnotetext{
${ }^{13}$ Entre eux se dressait l'argent. C'était un mur, une espèce de butoir qu'ils venaient heuter à chaque instant. C'était quelque chose de pire que la misère : la gêne, l'étroitesse, la minceur. (PEREC, 1965, p.76)/ Ils pouvaient certes parler d'autre chose, d'un livre récemment paru, d'un metteur en scène, de la guerre, ou des autres, mais il leur semblait parfois que leurs seules vraies conversations concernaient l'argent, le confort, le bonheur. (PEREC, 1965, p.77)
} 


\section{Les Choses \\ - une histoire des années soixante -}

Segundo Genette (1982, p.54), o título é todo enunciado breve e dedicado à paródia e já que "a forma mais vistosa e mais eficaz de alusão é a deformação paródica." ", devemos nos atentar para a escolha de Perec ${ }^{15}$. A princípio os dois em nada se parecem mas se pensarmos nas relações das histórias narradas em cada romance com o projeto de cada autor reconhecemos que a escolha de L'Éducation sentimentale não é ao acaso.

Antes de escrever o romance, Flaubert já manifestara seu desejo de "escrever uma história moral dos homens de sua geração" em carta à Mlle Leroyer de Chantepie, em 6 outubro de 1864. Para isso ele escolheu o gênero de aprendizagem (com os critérios já estabelecidos por Rastignac em Le Père Goriot) narrando a história de um jovem, cuja busca deveria the ensinar algo importanto para seu crescimento como homem. No entanto, reconhecemos em Frédéric Moreau um verdadeiro anti-herói, cuja busca é totalmente degradada, já que ele passa por diferentes fases de sua vida de estudante sem se comprometer realmente com nada e sua busca pelo amor de Mme Arnoux não o leva a nenhum amadurecimento ou aprendizagem, uma vez que ele ternima como um típico burguês, sem posição diante da sociedade.

Como já dissemos anteriormente, Perec atualiza o romance do séc XIX no contexto da geração de 60, quando o capitalismo e a lógica do mercado e do consumo já estão bastante enraizados. Há aqui também um anti-romance de formação, já que Jerôme e Sylvie empreendem uma busca degradada por riqueza, uma busca por seu próprio inimigo ("L'ennemi était invisible", p.91) que os mantém numa alucinação constante e ao final:

Suas vidas não tinham sido mais do que uma espécie de dança contínua sobre uma corda estendida, que não levava a lugar nenhum: um apetite vazio, um desejo $\mathrm{nu}$, sem limites e sem pontos de apoio. Sentiram-se esgotados. Partiram para se enterrar, para esquecer, para se apaziguar. (PEREC; NETTO (trad.), 1969, p.105)

Suas vidas eram como um hábito longo demais, como um tédio quase sereno: uma vida sem nada. ${ }^{16}$ (idem, p.119)

Les Choses só será o primeiro exemplo dessa sedução que Flaubert exerceu sobre Perec, mas como afirma Miguet "il n’y a plus trace d'une telle manière dans les oeuvres suivantes." (MIGUET, 1983, p. 138) A leitura de todo o Les Choses nos faz sentir o déjà-lu do livro de Flaubert, porém a história é completamente diferente, o sentido das cenas é totalmente inovado na proposta de Perec.

O estudo de L'Éducation sentimentale como modelo flaubertiano para Les Choses nos abre um leque de interpretações para este livro de Perec e nos permite a começar a traçar o olhar crítico do escritor sobre a geração de 1960, na França, e seu modo de "fazer literatura" com todas as questões que vinham surgindo desde os tempos de Flaubert. $\mathbf{c}^{\mathbf{g}}$

\footnotetext{
14 “(...) la forme la plus voyante et la plus efficace de l'allusion est la déformation parodique” (trad. nossa)

${ }^{15}$ Cf. tese de doutorado de Hans Hartje em que ele cita a lista de títulos criados por Perec no caderno intitulado "La Grande Aventure” que só mais tarde será Les choses. Hans Hartje, “Georges Perec, écrivain”, 1993, p.64.

16 «Leur vie n'avait été qu'une espèce de danse incessante sur une corde tendue, qui ne débouchait sur rien : une fringale vide, un désir nu, sans limites et sans appuis. Ils se sentaient épuisés. Ils partaient pour s'enterrer, pour oublier, pour s'apaiser.» (PEREC, 1965, p.123)/ «Leur vie était comme une triop longue habitude, comme un ennui presque serein : une vie sans rien. »(PEREC, 1965, p.139)
} 
Agradecimento: À FAPESP, pela bolsa concedida.

\section{Referências bibliográficas :}

BLOOM, Harold. A Angústia da Influência: uma teoria da poesia. Rio de Janeiro: Imago, 1991. 213p.

FLAUBERT, Gustave [1869]. L'Éducation sentimentale. Paris : Pocket Classiques, 1998.

A Educação sentimental, p.101-2, trad. rev. e adapt. pelo

Departamento Editorial de W. M. Jackson Inc.)

GENETTE, G. Palimpsestes - La Littérature au Second Degré. Paris: Seuil, 1982. pp.7-215. . "Silences de Flaubert”, Figures .Paris: Seuil, 1966. pp.223-43.

GIGNOUX, A. C. «De l'intertextualité à l'écriture » in Cahiers de Narratologie, n.o. 13 : Nouvelles Approches de 1'inntertextualité. Organização de Alain Tassel (1 septembre 2006). Disponível no site http://revel.unice.fr/cnarra/ (acesso em out/2006)

HARTJE, Hans. Georges Perec écrivant .Tese sob a orientação de Jacques Neefs. Université Paris VII, 1995. 194p.

HILL, L. «Perec à Warwick » in RIBIÈRE, Mireille (org), Parcour Perec - Colloque de Londres (mars 1988), Presses Universitaires de Lyon, 1990, pp.25-30.

LANSON, G. «La méthode de 1’Histoire Littéraire », «La fonction des influences étrangères dans le développement de la littérature française », "Sur la notion d'influence » in Essais de méthode de critique et d'histoire littéraire. Paris: Hachette, 1965. MIGUET, Marie. « Sentiments filiaux d’un prétendu parricide » in Poétique, n.o. 54, Paris: Seuil, 1983.

PEREC, Georges. Les Choses - une histoire des années soixante. Paris : Denoël, 1965.

. As coisas - uma história dos anos 60. Netto, T. C. (trad.). São Paulo: Ed. Nova Crítica, 1969. p.83.)

L. G. - une aventure des années soixante. Paris : Seuil, 1992. 183p.

PEREC, G. "Pouvoirs et Limites du romancier français contemporain » in RIBIÈRE, M (org).Parcours Perec - Colloque de Londres (mars 1988), Lyon : Presses Universitaires de Lyon, 1990.

PROUST, M. “À propos du 'style' de Flaubert”. In La Nouvelle Revue Française. 1er janvier 1920. Disponível no site http://pagesperso-orange.fr/jb.guinot/pages/Proust.html.

Acesso em 30/11/2005. 